\title{
The Spontaneous Hemin Release from Lumbricus terrestris Hemoglobin
}

\author{
M. L. Smith, ${ }^{1}$ J. Paul, ${ }^{2}$ P. I. Ohlsson, ${ }^{3}$ and K. G. Paul ${ }^{3}$ \\ IIATRIC Research Institute, 2330 South Industrial Park, Tempe, AZ 85282 U.S.A.; \\ ${ }^{2}$ Chemistry Department, Bilkent University, 06533 Bilkent-Ankara, Turkey; and 'University \\ of Ume̊̊, Department of Medical Chemistry and Biophysics, S-901 87 Ume̊̊, Sweden
}

\begin{abstract}
The slow, spontaneous release of hemin from earthworm, Lumbricus terrestris, hemoglobin has been studied under mild conditions in the presence of excess apomyoglobin. This important protein is surprisingly unstable. The reaction is best described as hemin released from the globin into water, followed by quick engulfment by apomyoglobin. The energetics of this reaction are compared with those of other types of hemoglobins. Anomalously low activation energy and enthalpy are counterbalanced by a negative entropy. These values reflect significant low frequency protein motion and dynamics of earthworm hemoglobin and may also indicate an open structure distal to the heme. This is also supported by the infrared spectrum of the carbonyl hemoprotein, which indicates several types of distal interactions with the hound $\mathrm{CO}$. The reported low heme to polypeptide ratio for this protein may be due to facile heme and hemin release by the circulating protein. COMP BIOCHEM Physiol 118A;4:1241-1245, 1997. (c) 1997 Elsevier Science Inc.
\end{abstract}

KEY WORDS. Hemoglobin, Lumbricus terrestris, earthworm, hemin, hemin transfer, protein dynamics, protein stability, infrared, carbon monoxide

\section{INTRODUCTION}

The circulatory hemoglobin of earthworm is present as a free protein, in contrast to vertebrates where $\mathrm{Hb}$ is contained within the erythrocyte membrane, and is much less protected from interactions with the vascular wall and foreign agents. This protein has a high molecular weight, 3.9 to $4.4 \mathrm{MDa}$, is a multimeric protein composed of at least five different subunit types, some of which do not appear to bind heme $(5,20)$. These are arranged in self-organized and self-limiting fashion into a gigantic protein containing about 220 subunits $(11,13)$. The large size of these extracellular oxygen carriers is thought to be necessary; $\mathrm{Hbs}$ of smaller mass would force the osmotic pressure higher than the organism could bear. These large Hbs exhibit high ligand-binding cooperativity with $\mathbf{n}_{50}$ from 3.3 for $L$. terrestris (18), up to 9.5 for Eisenia foetida and Pheretima hilgendorfi $\mathrm{Hbs}$, depending upon $\mathrm{pH}, \mathrm{Ca}^{2+}$ and $\mathrm{Zn}^{2+}$ concentrations $(6,8,9)$. In place of chloride ion and sugar phosphates, which are effectors of mammalian and avian $\mathrm{Hbs}, \mathrm{pH}$ and dibasic cations appear to play the roles of allosteric effectors

\footnotetext{
Address reprint requests to: M. L. Smith, Chuparoso Research, 1148 S. Quail St., Mesa, AZ 85206. Tel. +1-602-832-0622; E-mail: 76602.2047@ compuserve.com.

Abbreviations-Hemoglobin, $\mathrm{Hb}$; myoglobin, $\mathrm{Mb}$; apohemoglobin, apoHb; apomyoglobin, apoMb; holometmyoglobin, holoMb; Hill coefficient, $\mathbf{n}_{s_{0}}$; infrared, $\mathbb{R}$.

Received 25 January 1997; revised 16 April 1997; accepted 24 April
} 1997 for these Hbs. Isolated earthworm $\mathrm{Hb}$ appears to be an unstable hemoprotein which rapidly releases hemin into the solvent.

Free hemin and globin cannot be tolerated by higher vertebrates and can lead to a variety of complications through increased Heinz body formation including hemolytic anemia (1). It is known that the heme in $\mathrm{Hb}$ is rapidly oxidized to hemin by a range of drugs and common chemicals including phenols, hydrazines, and nitrites with clinical complications (7). Hemin is also continuously formed in the blood of apparently healthy individuals as a product of chloride assisted oxidation of hemoglobin at a rate of $1-2 \%$ daily (19). Using apoMb as the hemin sink, we have shown that the spontaneous release of hemin from the $\beta$ chains of human $\mathrm{Hb}$ and single point mutants is a continuous process with a half-life of only a few hours (14). This system measures only the hemin release and is independent of hemin apoMb combination (4).

Hemin transfer from an intact donor protein to an acceptor protein is illustrated in a reaction triangle in Fig. 1. Some donor- or holoproteins can he observed in two forms: a form that displays the normal, native activity and a form that displays much less enzymatic activity. The barrier for hemin release is measurably lower for the inactive form of hemoprotein than from the active, but slower hemin releasing holoprotein. The active and inactive holoforms occupy the two left corners of the transfer triangle. The equilibrium between these two forms of holoprotein can he perturbed 


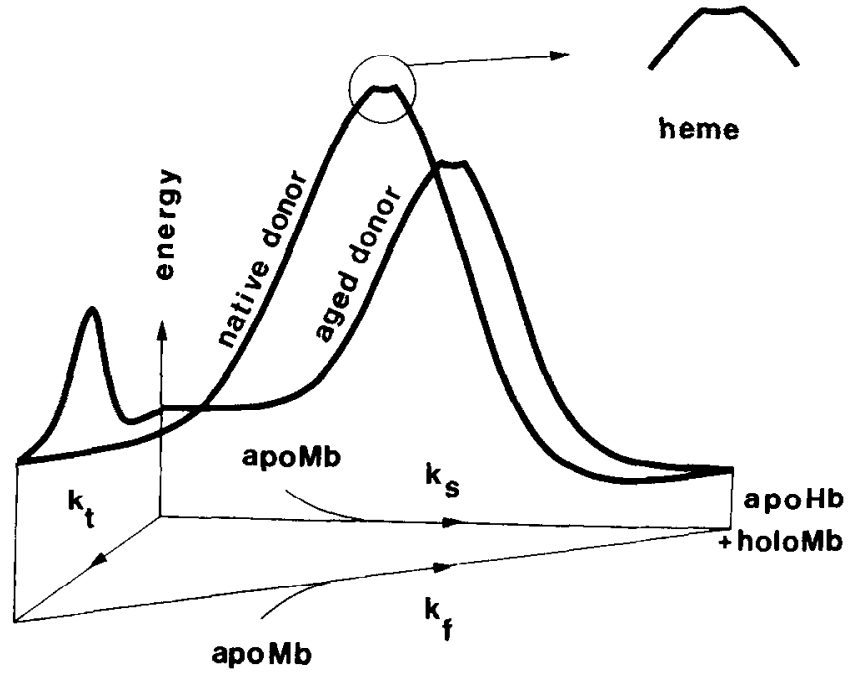

FIG. 1. Diagrammatic relationship between the protein species and energies of hemin release. Note that the energy of the products, at right, are only slightly lower than the energy of the reactants, at left. The activation energy, at the top, is many times larger than the overall reaction energy.

by changes in temperature, prolonged aqueous storage or addition of certain ligands to the system. Addition of apomyoglobin to the system moves the equilibrium toward the third corner, with production of holoMb and apodonor protein. It was previously shown that the hemin leaves the donor protein during spontaneous fission and the apoMb does not interact with the donor protein (15). The observed energetics are, therefore, characteristic only of the donor protein. We have observed at least two forms of earthworm $\mathrm{Hb}$, both rapidly undergo fission under mild conditions, exhibiting relatively low activation energies and enthalpies. The rate of hemoprotein fission is greater for the oxidized form of earthworm hemoglobin than for any other protein so far observed.

\section{EXPERIMENTAL}

About 100 earthworms were washed in water, decapitated and the blood squeezed into a beaker containing a few $\mathrm{ml}$ of standard buffer; $50 \mathrm{mM}$ phosphate, $1 \mathrm{mM}$ EDTA, $\mathrm{pH} 7.0$. The mixture was centrifuged, filtered then concentrated to $1.5 \mathrm{mM}$ heme under nitrogen. Part of this preparation was gassed with $\mathrm{CO}$ for $15 \mathrm{~min}$, injected into an IR cell with $\mathrm{CaF}_{2}$ windows and the IR spectrum collected on a DIGILAB 15/90E spectrometer fitted with a liquid nitrogen cooled detector. Citrated blood from a domestic rabbit was centrifuged and washed several times with isotonic saline. The packed red blood cells were gassed with CO for $15 \mathrm{~min}$ before injection into the IR cell. The data were resolved into component curves using the program SAAM II, courtesy of the University of Washington. The remainder of the earthworm $\mathrm{Hb}$ was chromatographed down a $40 \times 1 \mathrm{~cm}$ column of G-25 Sephadex ${ }^{\circledR}$ (Pharmacia) equilibrated with standard buffer. This portion was frozen in liquid nitrogen, as beads, until further use. Earthworm hemoglobin can be chromatographed after thawing with no observable insoluble residue and the elution profile is consistent with high molecular weight and little subunit dissociation.

A typical kinetic experiment was begun by thawing a few beads of the frozen $\mathrm{Hb}$, while the buffer was incubated in a thermostated quartz cuvette in a Beckmann DU-7 spectrophotometer. The apoMb was separately incubated for 15 $20 \mathrm{~min}$ in a water bath. A small amount of the earthworm $\mathrm{Hb}$ was added to the buffer, then heme was always oxidized to hemin by addition of a single grain of $\mathrm{K}_{3} \mathrm{Fe}(\mathrm{CN})_{6}$. The reaction was initiated by addition of a small amount of apoMb $(0.5 \mathrm{mM})$ and the formation of holoMb followed at $409 \mathrm{~nm}$ overnight, which was at least three half-lives. Some reactions were followed by repeated scanning from 370 to $450 \mathrm{~nm}$; isosbestic points were observed at 391 and $425 \mathrm{~nm}$. From 25 to 52 data pairs were collected for each determination and the data were analyzed using the programs SYS$\mathrm{TAT}^{\circledast}$ and RS $/ 1^{\circledast}$. A portion of the earthworn hemoglobin was aged by refrigeration in standard buffer from 10 to 14 days. Rabbit maintenance, procedures and expcrimentation were conducted in conformity with humane guidelines of Sweden.

\section{RESULTS}

The infrared spectrum of carbonyl earthworm $\mathrm{Hb}$ exhibits a strong band with a maximum at $1951 \mathrm{~cm}^{-1}$, which is the energy commonly observed for COHbs (12). This spectrum can be resolved into at least four bands, three of these being of lower energy and strength than the primary band at 1951 $\mathrm{cm}^{-1}$, Fig. 2. The band width, at half height, of the primary band at $1951 \mathrm{~cm}^{-1}$, is $23 \mathrm{~cm}^{-1}$, which is much broader than observed for most other $\mathrm{Hbs}$, which exhibit narrow bands, $8 \mathrm{~cm}^{-1}$, at $1951 \mathrm{~cm}^{-1}$ (12). Much smaller bands were observed at 1936, 1913, and $1903 \mathrm{~cm}^{-1}$, though this lowest energy absorbance is very small and may not be real.

The hemin release data were best fit as either a single first order or two simultaneous first order hemin transfers, by both programs. Close inspection of the plotted data revealed three or four simultaneous reactions of very slightly different rates, however the curve fitting procedures used did not give us greater confidence in results from a multiple first order fit than the simple fit of a single first order reaction, so the single rate constant is used in discussion. In addition, a slow, linear absorbance increase was observed at the end of the experiments which was presumably due to precipitation of some apoHb and made estimation of the end absorption difficult, as has been observed for human $\mathrm{Hb}$ (14). This slow reaction was not further studied.

The overall rate constant at $298^{\circ} \mathrm{K}, 1.9 \times 10^{\prime} \mathrm{min}$ ', was larger than for any other native protein so far studied and about twice as fast as hemin release from human I Ib $\mathrm{A}$ 


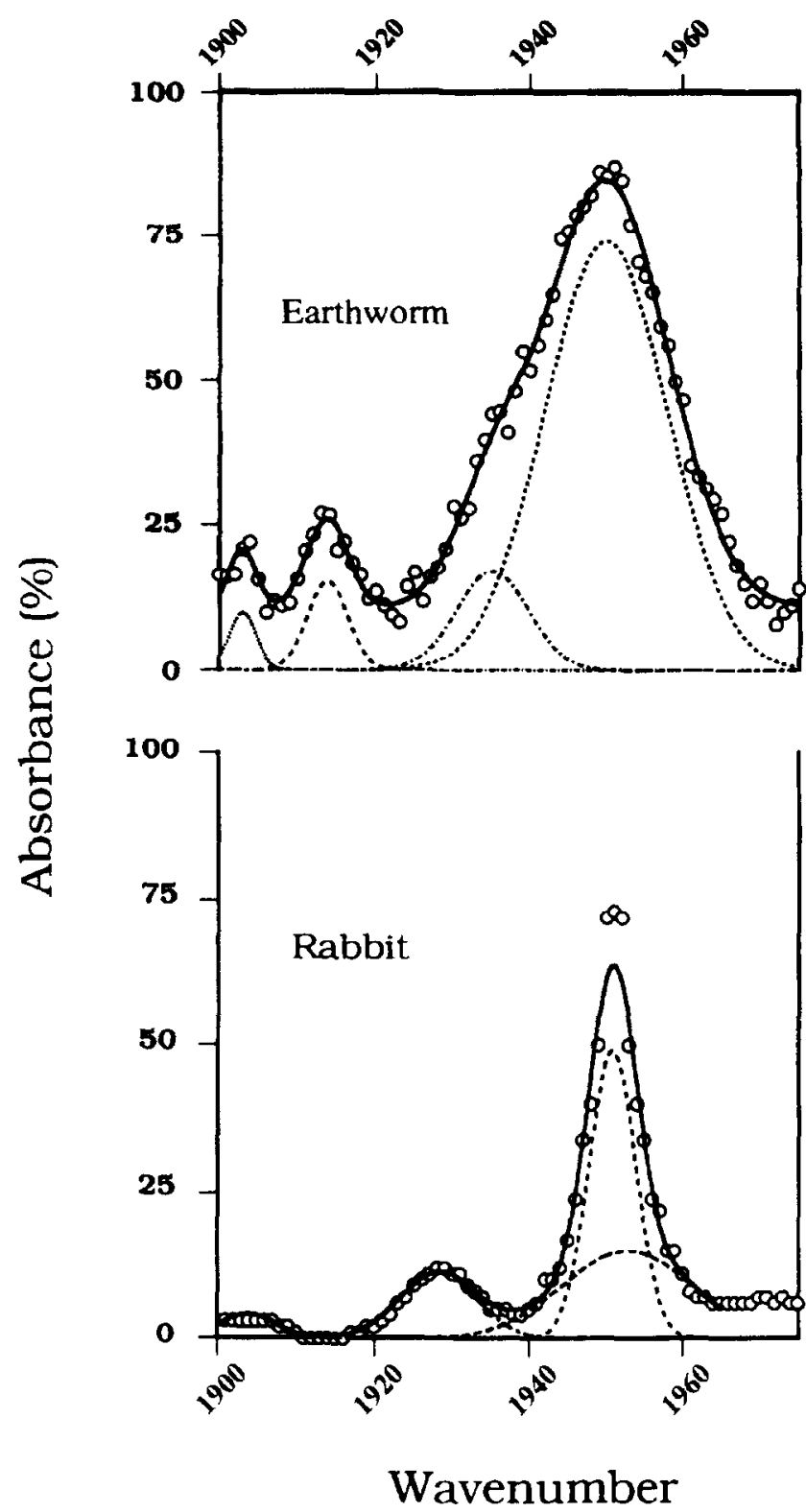

FIG. 2. Infrared spectra of earthworm $\mathrm{COHb}$, top, and domestic rabbit $\mathrm{COHb}$, in the $\mathrm{CO}$ stretch region. The circles are the data points used for curve resolving. The dashed lines are the resolved curves and the solid lines represent the linear combinations of the resolved curves.

(Table 1). The Ahrrenius plots of the release rates as a function of inverse temperature are shown in Fig. 3. The activation energy for the isolated earthworm $\mathrm{Hb}$ is $89 \pm 9 \mathrm{~kJ}$ $\mathrm{mol}^{-1}$ and only $50 \pm 10 \mathrm{~kJ} \mathrm{~mol}^{-1}$ for the aged protein, both being much lower than fission of $\mathrm{Hb} \mathrm{A} \beta$ chains, $124 \mathrm{~kJ}$ $\mathrm{mol}^{-1}$. These low activation energies are counterbalanced by negative activation entropies. The free energies of activation, $\Delta \mathrm{G}^{\circ}+$, were calculated as 93 and $91 \mathrm{~kJ} \mathrm{~mol}^{-1}$ for the freshly isolated and aged proteins, respectively, which is insignificantly lower than observed for $\mathrm{Hb} \mathrm{A} \beta$ chains or legume $H$ h. This separation of free energy into enchalpy and entropy is strictly valid only for rigid potentials and care should be taken with interpretation of these quantities.

\section{DISCUSSION}

The IR spectrum indicates the binding site for gaseous ligands in earthworm $\mathrm{Hb}$ is little different from other $\mathrm{COHhs}$, consistent with a proximal histidyl (ligand 5) to the heme $\mathrm{Fe}(\mathrm{II})$ and a distal histidyl group neighhoring the $\mathrm{CO}$ for most subunits. The minor CO strerch at $1936 \mathrm{~cm}^{-1}$ is consistent with distal histidyl substitution by glutamyl, as in the opossum (Didelphis marsupialis) with $\gamma \mathrm{CO}$ at $1943 \mathrm{~cm}^{-1}$ or with a distal situation similar to that of domestic rabhit with $\gamma \mathrm{CO}$ at $1929 \mathrm{~cm}^{-1}$, possibly caused by a "tighter fit" of this distal group with the distal histidyl (12). The CO stretches of peroxidases with histidyl as L5 and histidyl and arginyl residues distal to the $\mathrm{Fe}$ (II) are ohserved from 1938 down to $1903 \mathrm{~cm}^{-1}$, some of the $\mathrm{CO}$ stretch(es) of $\mathrm{CO}$ cytuchrome P450 with a cystidyl L5 are observed at lower energies than $\mathrm{COHb}(10)$. The absence of significant ahsorbance between 1960-1970 $\mathrm{cm}^{\prime}$ indicates that the protein surrounding the heme was primarily in the native conformation; $\mathrm{CO}$ hemoproteins from proteins reconstiruted with heme and containing some nonnative hemoprorein, almost invariably exhibit a band in this region despite chromatography to remove excess hemin (16), denaturation also results in absorbance hetween $1960-1970 \mathrm{~cm}^{-1}(10)$.

Table 1 also presents the results from studies of the hemoprotein fission of several oxygen carriers and peroxidases, which exhibit a $\Delta \mathrm{G}^{\circ} \dagger$ about $10 \mathrm{~kJ}$ mol' larger than any oxygen carrier. We suggest that this difference is due to the difference in water coordination in the heme pocket. The highly polar groups present in the pocket of peroxidases appear to control the water(s) in a manner that both increases electron availability at iron and discourages hemoprotein fission. It is interesting that the earthworm Hh exhibits the shortest half life for protein fission of any native hemoprotein so far examined. There are two possible reasons for this property (a) the flexibility of the polypeptide, with demands for communication between subunits that is required in $\mathrm{Hbs}$ for cooperative dioxygen binding (h) the high mass of the Hb moleculc which offers more channels for concentrating energy to the heme pocket required for hemin release. Rearson (a) is supported by the IR data of $23 \mathrm{~cm}^{-1}$ hand width for the primary absorbance, which suggests a much more open distal pocket, allowing more facile heme release. There also appears to he a trend towards higher rates of protein fission with increasing molecular weight, supporting reason (b). Perhaps the low frequency dynamics with high kinetic energies are more allowed in high MW proteins. If so, other invertebrate, giant Hhs are probahly also relatively unstable.

Previous studies indicated that the energy barrier for hemin release consists of two parts; Fe-L5 hond breakage and hemin solvation (15). The free energies of hemin and por- 
TABLE 1. Kinetic parameters for hemin release from Lumbricus terrestris, other hemoglobins and a peroxidase

\begin{tabular}{|c|c|c|c|c|c|}
\hline Protein & $\begin{array}{c}\text { Temp. range } \\
\left({ }^{\circ} \mathrm{C}\right)\end{array}$ & $\begin{array}{l}\text { Rate constant } \\
\left(\min ^{-1} \times 10^{3}\right)\end{array}$ & $\begin{array}{c}\Delta \mathbf{H}^{\circ} \dagger \\
(\mathbf{k J} / \mathbf{m o l})\end{array}$ & $\begin{array}{c}\Delta \mathrm{G}^{\mathrm{o}} \dagger \\
(\mathrm{kJ} / \mathrm{mol})\end{array}$ & $\begin{array}{c}\Delta \mathbf{S}^{\circ}{ }^{\circ} \\
\left(\mathrm{J} / \mathbf{m o l}{ }^{\circ} \mathbf{K}\right) \\
\end{array}$ \\
\hline L. terrestris & $14-30$ & $19 \pm 4$ & $87 \pm 9$ & 93 & -22 \\
\hline Aged terrestris & $20-37$ & $38 \pm 6$ & $48 \pm 10$ & 91 & -146 \\
\hline Human $\mathrm{Hb} \mathrm{A}$ & $25-42$ & $7 . \overline{7}$ & 120 & 95 & 82 \\
\hline Glycine soya (soybean) $\mathrm{Hb}$ & $>23$ & 7.1 & 130 & 95 & 117 \\
\hline Armoracia rusticana (horseradish pcroxidasc) C & $30-45$ & 0.24 & 131 & 104 & 91 \\
\hline
\end{tabular}

phyrin fission differ by about $10 \mathrm{~kJ} \mathrm{~mol}^{-1}$, which was assigned to the Fe-L5 bond. The remaining $80-90 \mathrm{~kJ} \mathrm{~mol}^{-1}$ was interpreted being due to the energy required to solvate porphyrin-that is the difference in surface energies of aquated porphyrin and porphyrin buried within the protein. The $\Delta G^{\circ}+$ found here for the native earthworm $\mathrm{Hb}$ is consistent with this interpretation. Facile hemin exchange is the mechanism used to control the activity levels of the proteins tryptophan-2,3-dioxygenase (3), and prostoglandin endoperoxidase synthetase (17). Heme release may not be important for the well-being of $L$. terrestris, but a continuing problem to be tolerated in exchange for a lowered osmotic pressure and a freely circulating $\mathrm{Hb}$.

The results show that spontaneous release of hemin occurs even from an important protein that freely circulates in blood. The results also show that oxidized earthworm $\mathrm{Hb}$ undergoes hemoprotein tission more readily than any other hemoprotein and this rate of self destruction increases dur-

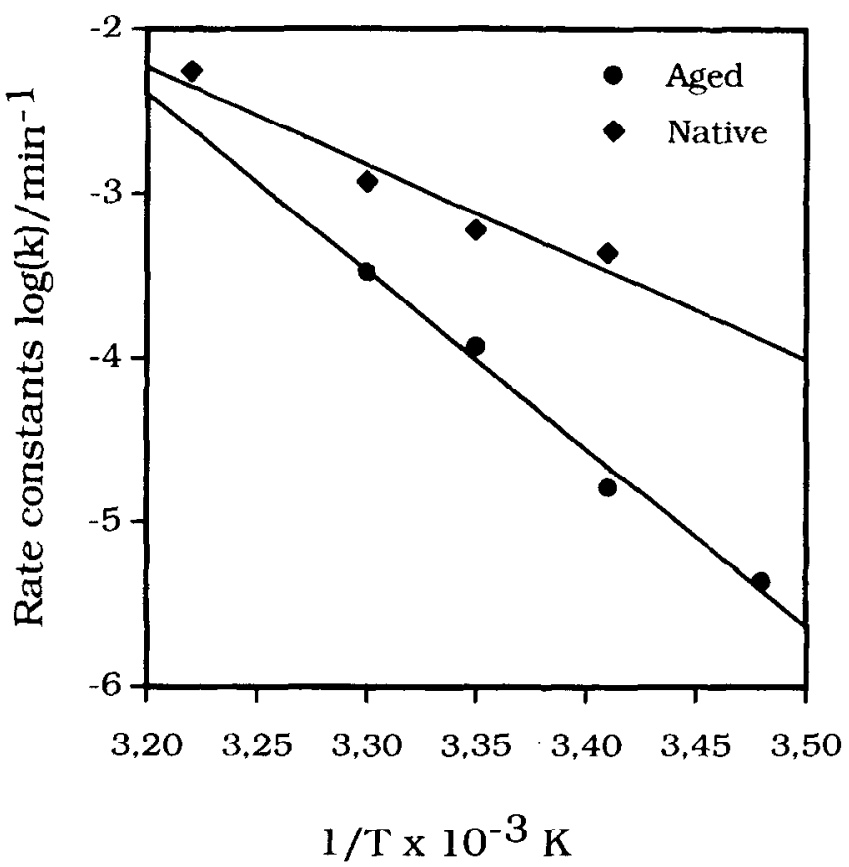

FIG. 3. Arrhenius plot of the first order rate constants for hemin release from native $(\bullet)$ and aged $(\Theta)$ earthworm $\mathrm{Hb}$, with the temperature ranges as given in Table 1 . The lines shown are the linear best fits. ing storage. This is probably due to a combination of a ligand binding site more open to solvent than other hemoglobins and to greater kinetic energies associated with low frequency molecular motions in giant proteins. This may be a partial explanation for the reported unsaturation of heme binding sites for this oxygen carricr (20).

We wish to thank Magnus Hultin for performing the curve resolving. This work was supported in part by grants from Norrlands Gasaktiebolag, Magn. Bergualls Stiftelse, and the Swedish Medical Research Council ( $3 \chi-6522,7130)$.

\section{References}

1. Bunn, H.F.; Forget, B.G. Hemoglobin: Molecular, Genetic and Clinical Aspects. Philadelphia, PA: W.B. Saunders Company; $1986: 573-587$.

2. Darawshe, S.; Tsafadyah, Y.; Daniel, E. Quaternary structure of erythrocruorin from the nemotode Ascaris suum. Evidence for unsaturated haem-hinding sites. Biochem. J. 242:689-694; 1987.

3. Feigelson, P.; Greengard, O. A microsomal iron-porphyrin activator of rat liver tryptophan pyrrolase. J. Biol. Chem. 236: $153-157 ; 1961$

4. Hargrove, M.S.; Barrick, D.; Olson, J.S. The association rate constant for heme binding to glohin is independent of protein structure. Biochemistry 35:11293-11299;1966.

5. Hendrickson, W.A.; Royer, W.E., Jr. Principles in the assembly of annelid erythrocruorins. Biophys. J. 49:177-189;1986.

6. Igarashi, Y.; Kimura, K.; Kajita, A. Calcium-dependent allosteric modulation of the giant hemoglobin from the terrestrial oligochate, Eisenia foetida. Biochem. Int. 10:611-618;1985.

7. Nagel, R.L.; Ranney, H.M. Drug induced oxidative denaturation of hemoglobin. Sem. Hematol. X:269-78;1973.

8. Ochiai, T. Dissociation and oxygen equilibrium properties of earthworm hemoglobin. Arch. Biochem. Biophys. 226:111$117 ; 1983$.

9. Ochai, T.; Hoshind, S.; Usuki, I. Zinc as modulator of oxygenation function and stabilizer of quaternary structure in earthworm hemoglobin. Biochim. Biophys. Acta 1203:310$314 ; 1993$.

10. O'Keeffe, D.H.; Ebel, R.E.; Peterson, J.A.; Maxwell, J.C.; Caughey, W.S. An infrared spectroscopic study of catbon monoxide bonding to ferrous cytochrome P-450. Biochemistry $17: 5845-5852 ; 1978$.

11. Ownby, D.W.; Zhu, H.; Schneider, K.; Beavis, R.C.; Chiat, B.T.; Riggs, A.F. The extracellular hemoglohin of the earthworm Lumbricus terrestris. Determination of subunit stoichiometry. J. Biol. Chem. 268:13539-13547;1993.

12. Potter, W.T.; Hazzard, J.H.; Choc, M.G.; Tucker, M.P.; Caughey, W.S. Infrared spectra of carbonyl hemoglobins: 
Characterization of dynamic heme pocket conformers. Biochemistry 29:6283-6295;1990.

13. Royer, W.E., Jr.; Hendrickson, W.A. Molecular symmetry of Lumbricus erythrocruorin. 263:13762-13765;1988.

14. Smith, M.L.; Hjortsherg, K.; Roméo, P.H.; Rosa, J.; Paul, K.G. Mutant hemoglobin stability depends upon location and nature of single point mutation. FEBS Lett. 169:147-150;1984.

15. Smith, M.L.; Paul, J.; Hjortsberg, K.; Ohlsson, P.I.; Paul, K.G. Hemeprotein fission under nondenaturing conditions. Proc. Nat. Acad. Sci. USA 88:882-886;1991.

16. Smith, M.L.; Paul, J.; Ohlsson, P.I.; Paul, K.G. Correlation between reduction potential, $\mathrm{CO}$ stretch frequency and $\mathrm{CO}$ half-bandwidth in hemoproteins. Biochemistry 23:6776$6785 ; 1984$.

17. Uuno. R.; Shimizu, T.; Kondo, K.; Hayaishi, O. Activation mechanism of prostaglandin synthetase hy hemoproteins. J. Biol. Chem. 257:5584 -..5588;1982.

18. Vinogradov, S.N.; Sharma, P.K.; Qabar, A.N.; Wall, J.S.; Westrick, J.A.; Simmons, J.H.; Gill, S.J. A dodecamer of globin chains is the principal functional subunit of the extracellular hemoglobin of Lumbricus terrestris. J. Biol. Chem. 266: $13091-13096 ; 1991$.

19. Wallace, W.J.; Maxwell, J.C.; Caughey, W.S. A role for chloride in the autoxidation of hemoglobin under conditions similar to those in erythrocytes. Biochem. Biophys. Res. Comm. $57: 1104-1110 ; 1974$.

20. Zhu, H.; Hargrove, M.; Xie, Q.; Nuzaki, Y.; Linse, K.; Smith, S.S.; Olson, J.S.; Riggs, A.F. Stuichiometry of subunits and heme content of hemoglohin from the carthworm Lumbricus terrestris. J. Biol. Chem. 271:29999-30006;1996. 